\title{
Ingestion of plastics at sea: does debris size really matter?
}

\author{
Julia Reisser ${ }^{1 *}$, Maira Proietti ${ }^{2}$, Jeremy Shaw ${ }^{3}$ and Charitha Pattiaratchi' \\ ${ }^{1}$ School of Civil, Environmental, and Mining Engineering, The UWA Oceans Institute, University of Western Australia, Perth, WA, Australia \\ 2 Instituto de Oceanografia, Universidade Federal do Rio Grande, Rio Grande, Brazil \\ ${ }^{3}$ Centre for Microscopy, Characterisation, and Analysis, University of Western Australia, Perth, WA, Australia \\ *Correspondence: jureisser@gmail.com
}

\section{Edited by:}

Rathinam Arthur James, Bharathidasan University, India

Reviewed by:

Sabarathinam Chidambaram, Annamalai University, India

Keywords: microplastics, marine debris, plastic ingestion, zooplankton grazing, copepods

Marine microplastics ( $<5 \mathrm{~mm}$ in length) can contain high loads of additives and adsorbed pollutants, and may be a threat to marine food webs due to their ingestion by organisms at the base of the food chain (http://www.unep.org/yearbook/). Most of our knowledge on plastic ingestion by zooplankton has been obtained through experiments assuming that plastic particles have to be smaller than the organism's feeding apparatus for this type of interaction to occur (Cole et al., 2013). However, we propose that this is not a rule.
By examining the surface of millimetersized marine plastics using a scanning electron microscope, we observed a diverse range of fouling organisms, and a variety of intriguing pits and scraping marks of unknown origin-see details in Reisser et al. (2014b) and s.e.m. images at Reisser et al. (2014a). Here we suggest that some of these plastic surface textures are feeding marks produced by invertebrates grazing upon the plastic biofilm.

We observed sub-parallel linear scrapes with $5-14 \mu \mathrm{m}$ spacing (Figures 1A,C), which is similar to typical distances between teeth of the mandibular gnathobases of copepods (Michels et al., 2012). The thinner and shallower marks around the linear scrapes could have been formed by filamentous microstructures present on their gnathobases. Copepods are an abundant planktivorous group and possess strong feeding apparatuses to feed upon organisms such as diatoms (Michels et al., 2012). Some pelagic species have flexible feeding habits, and can feed on sea-ice algae (Brierley and Thomas, 2002),

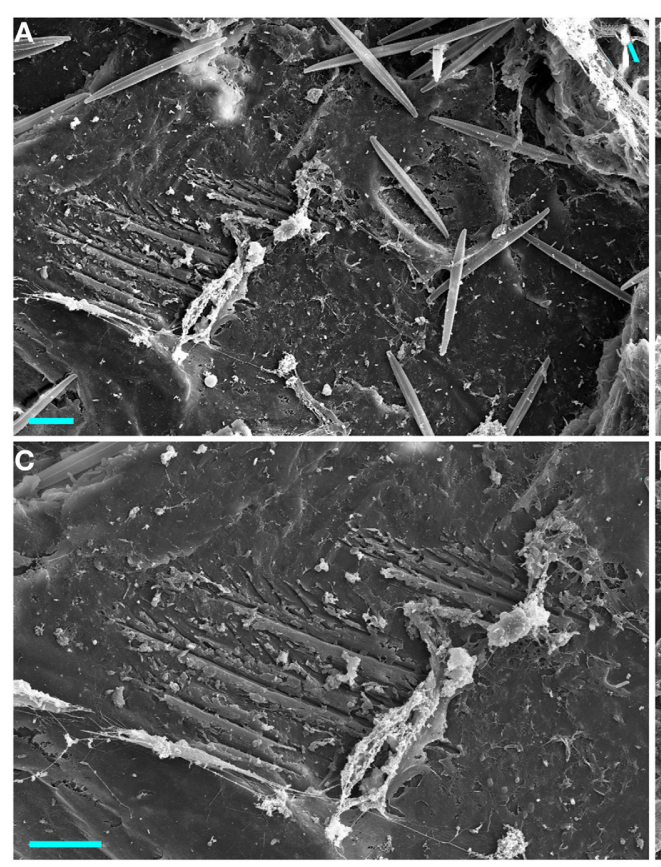

FIGURE 1 | Scrapes putatively identified as feeding marks. (A) Linear scrape marks on a $2.3 \mathrm{~mm}$ long plastic debris with a high load of diatoms. (B) Rounded scrape marks on a $6 \mathrm{~mm}$ long plastic with a unidentified

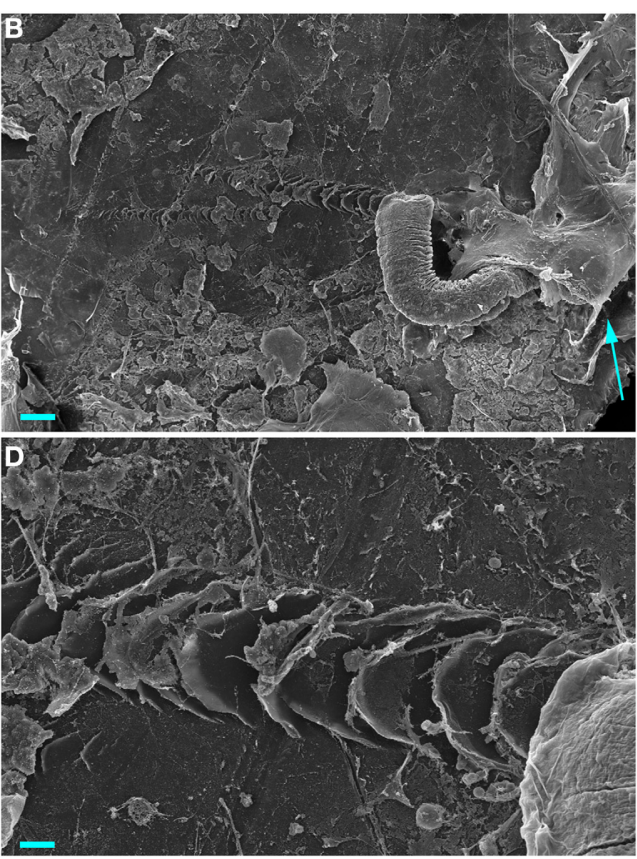

marine worm. Arrow indicates unknown structure partially covering the worm. (C) zoom on scraping displayed in (A). (D) zoom on scraping shown in (B). Scale bars $=10 \mu \mathrm{m}$ (A,C), $100 \mu \mathrm{m}$ (B), $20 \mu \mathrm{m}$ (D) 
fecal pellets (Noji et al., 1991; Gonzalez and Smetacek, 1994), and marine snow particles (Turner, 2002). We suggest that these copepods could also feed upon biofilm of plastic debris, which is often rich in "epiplastic" diatoms (Carson et al., 2013; Reisser et al., 2014b).

We also observed peculiar rounded marks close to an unidentified marine worm (Figures 1B,D), which was partially covered by an unknown structure (indicated by the arrow) possibly secreted by the animal. These unique scraping marks were also noted on two other plastic pieces that did not have any visible animals, but possessed structures similar to the one covering the worm in Figure 1B. These results suggest that feeding on plastic biofilm is not restricted to zooplankton, and possibly occurs with rafting organisms such as amphipods, gastropods, and chitons, which are known to associate with floating debris such as plastics (Winston et al., 1997).

Small portions of the plastic particles were apparently removed, and perhaps ingested, during these putative grazing activities (Figure 1). Thus, our hypotheses are that (1) plastic biofouling induces plastic ingestion, and (2) plastic pieces must not necessarily be smaller than the organism for a feeding interaction to occur. The latter hypothesis has already been suggested for large items, as $15.8 \%$ of drifting plastic objects in Hawaii displayed a variety of vertebrate bite marks (Carson, 2013).

Experiments exposing zooplanktonic organisms to millimeter-sized plastics with biofilm may document whether they are capable of handling these particles, creating such feeding marks. By exposing neustonic zooplankton to fresh pieces of brittle plastic debris, researchers could possibly document this new type of feeding behavior (e.g., by filming), and detect plastic bits co-ingested with biofilm grazing (e.g., by examining fecal pellets).

Due to their rapid growth and nutritional value, biofilms on plastic debris may be a significant new food source for invertebrates, particularly in the oligotrophic waters within subtropical gyres, where plastic contamination levels are particularly high. The impacts related to this new type of feeding interaction remain unclear, but are likely negative since plastics pose chemical and physical threats to their "predators/grazers" (Wright et al., 2013). These impacts could include effects on food webs, since plastic-associated pollutants and additives could be transferred to the biofilm and moved up the food chain of plastic "predators/grazers." The implications of plastic biofilm ingestion, particularly in terms of pollutant transfer and health effects should also be investigated.

\section{REFERENCES}

Brierley, A. S., and Thomas, D. N. (2002). Ecology of Southern Ocean pack ice. Adv. Mar. Biol. 43, IN171-IN174. doi: 10.1016/S0065-2881(02) 43005-2

Carson, H. S. (2013). The incidence of plastic ingestion by fishes: from the prey's perspective. Mar. Pollut. Bull. 74, 170-174. doi: 10.1016/j.marpolbul. 2013.07.008

Carson, H. S., Nerheim, M. S., Carroll, K. A., and Eriksen, M. (2013). The plastic-associated microorganisms of the North Pacific Gyre. Mar. Pollut. Bull. 75, 126-132. doi: 10.1016/j.marpolbul. 2013.07.054

Cole, M., Lindeque, P., Fileman, E., Halsband, C., Goodhead, R. M., Moger, J., et al. (2013). Microplastic ingestion by zooplankton. Environ. Sci. Technol. 47, 6646-6655. doi: 10.1021/es400663f

Gonzalez, H. E., and Smetacek, V. (1994). The possible role of the cyclopoid copepod Oithona in retarding vertical flux of zooplankton faecal material. Mar. Ecol. Prog. Ser. 113, 233-246. doi: 10.3354/meps113233

Michels, J., Vogt, J., and Gorb, S. N. (2012). Tools for crushing diatoms-opal teeth in copepods feature a rubber-like bearing composed of resilin. Sci. Rep. 2:465. doi: 10.1038/ srep00465
Noji, T. T., Estep, K. W., Macintyre, F., and Norrbin, F. (1991). Image analysis of faecal material grazed upon by three species of copepods: evidence for coprorhexy, coprophagy and coprochaly. J. Mar. Biol. Assoc. UK 71, 465-480. doi: $10.1017 /$ S0025315400051717

Reisser, J., Shaw, J., Hallegraeff, G., Proietti, M., Barnes, D., Thums, M., et al. (2014a). Data from: Millimeter-Sized Marine Plastics: a New Pelagic Habitat for Microorganisms and Invertebrates. Figshare. Available online at: http://figshare.com/ articles/Data_from/1043987

Reisser, J., Shaw, J., Hallegraeff, G., Proietti, M., Barnes, D. K., Thums, M., et al. (2014b). Millimeter-sized marine plastics: a new pelagic habitat for microorganisms and invertebrates. PLoS ONE 9:e100289. doi: 10.1371/journal.pone. 0100289

Turner, J. T. (2002). Zooplankton fecal pellets, marine snow and sinking phytoplankton blooms. Aquat. Microb. Ecol. 27, 57-102. doi: 10.3354/ame027057

Winston, J. E., Gregory, M. R., and Stevens, L. M. (1997). "Encrusters, epibionts, and other biota associated with pelagic plastics: a review of biogeographical, environmental, and conservation issues," in Marine Debris: Sources, Impacts, and Solutions, eds J. M. Coe and D. B. Rogers (New York, NY: Springer), 81-97.

Wright, S. L., Thompson, R. C., and Galloway, T. S. (2013). The physical impacts of microplastics on marine organisms: a review. Environ. Pollut. 178 , 483-492. doi: 10.1016/j.envpol.2013.02.031

Conflict of Interest Statement: The authors declare that the research was conducted in the absence of any commercial or financial relationships that could be construed as a potential conflict of interest.

Received: 11 November 2014; accepted: 18 November 2014; published online: 03 December 2014.

Citation: Reisser J, Proietti M, Shaw J and Pattiaratchi $C$ (2014) Ingestion of plastics at sea: does debris size really matter? Front. Mar. Sci. 1:70. doi: 10.3389/fmars. 2014.00070

This article was submitted to Marine Pollution, a section of the journal Frontiers in Marine Science.

Copyright (c) 2014 Reisser, Proietti, Shaw and Pattiaratchi. This is an open-access article distributed under the terms of the Creative Commons Attribution License (CC BY). The use, distribution or reproduction in other forums is permitted, provided the original author(s) or licensor are credited and that the original publication in this journal is cited, in accordance with accepted academic practice. No use, distribution or reproduction is permitted which does not comply with these terms. 